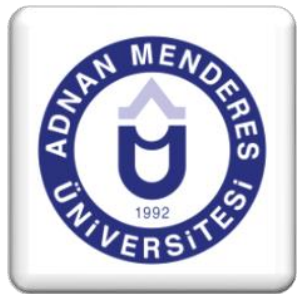

\section{Bist 30 Endeksinde Entropi Ve Yüksek Momentlerle TOPSIS Ve PROMETHEE Tabanlı Çok Amaçı Portföy Seçimi Modeli Önerisi $^{1}$}

\author{
Osman PALA ${ }^{2}$, Mehmet AKSARAYLI ${ }^{3}$
}

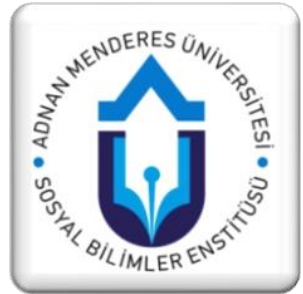

\title{
ÖZET
}

Modern dönemde portföy seçimi, finansal karar vericilerin ilgilendiği ve önceden tanımlı kısıtlamalar ile hedefler doğrultusunda optimum portföy seçimi olarak tanımlanabilecek, finansın önemli bir konusudur. Portföyler, getirileri politik kriz, finansal dalgalanmalar ve teknolojik gelişmeler gibi farklı olaylardan etkilenebilecek birden fazla sayıda hisse senedinden oluşmaktadır. Markowitz tarafından tanımlanan Modern Portföy Teorisi ve Ortalama Varyans modeli sayesinde portföy riskinin düşürülebilmesi ilk defa mantıklı bir yapıya oturmuştur. Teoriye göre karar verici, portföy riskini kendi aralarında pozitif korelasyona sahip olan hisse senetlerini birlikte portföye dahil etmeyerek düşürebilmektedir. Çalışmada, portföy seçim problemi için iki aşamalı çok amaçlı portföy seçim modeli önerilmiştir. İlk olarak, Ortalama Varyans modeli ile Pareto optimum portföyler elde edilmiştir. Sonrasında ise TOPSIS ve PROMETHEE yöntemleri kullanılarak yatırımcı tipine göre Pareto optimum portföyler sıralanmıştır. Entropi ve yüksek dereceden momentler, Pareto portföyleri sıralarken kriter olarak kullanılmıştır. Test periyodunda Pareto optimum portföylerin getiri performansları, portföy performans ölçütlerine göre değerlendirilmiş ve değerlendirme sonuçları TOPSIS ve PROMETHEE sıralama sonuçları ile kıyaslanmıştır. Uygulanan istatistik testleri sonucu, önerilen PROMETHEE modelinin daha etkin sonuçlar verdiği gözlenmiştir.

Anahtar Kelimeler ; Portföy Optimizasyonu; Pareto Stralama, PROMETHEE, TOPSIS.

Jel Kodlart ～; C610,C100,G110.

\section{A Proposed Multi Objective Portfolio Selection Model Based On Entropy And Higher Moments With TOPSIS And PROMETHEE In Bist 30 Index} \begin{abstract}
In the modern period, portfolio selection is an important topic of finance, which can be defined as optimum portfolio selection by financial decision makers and with predefined constraints and targets. Portfolios consist of multiple stocks that can be affected by different events such as political crisis, financial fluctuations and technological developments. It is the first time that a portfolio structure has been able to be reduced thanks to the Modern Portfolio Theory and the Mean-Variance model, as described by Markowitz. According to the theory, the decision maker can reduce the portfolio risk by not including the portfolio which has a positive correlation among themselves. In the study, a two-stage multi-attribute portfolio selection model was proposed for the portfolio selection problem. First, Pareto optimal portfolios were obtained with the Mean Variance model. Afterwards, Pareto optimum portfolios are ranked according to investor type by TOPSIS and PROMETHEE methods. Entropy and higher moments are used as criteria for ranking Pareto portfolios. In the test period, the return performances of Pareto optimum portfolios were evaluated according to the portfolio performance criteria and the evaluation results were compared with TOPSIS and PROMETHEE rankings. The results of the applied statistical tests show that the proposed PROMETHEE model gives more effective results.
\end{abstract}

Keywords $\quad$; Portfolio Optimization, Pareto Ranking, PROMETHEE, TOPSIS

Jel Codes $\quad$; C610,C100,G110.

\footnotetext{
Bu çalışma EUREFE 2017'de bildiri olarak sunulmuştur.

2 Dokuz Eylül Üniversitesi İktisadi ve İdari Bilimler Fakültesi Ekonometri Bölümü, 0 (232) 301 02 71, osman.pala@deu.edu.tr 3 Dokuz Eylül Üniversitesi İktisadi ve İdari Bilimler Fakültesi Ekonometri Bölümü, 0 (232) $301 \quad 02 \quad 81$, mehmet.aksarayli@deu.edu.tr
} 


\section{Giriș}

Portföy seçimi, yatırımcılar ve finans kuruluşları için her dönem önemli bir konu olmuştur. Portföy seçim problemi, her biri risk bulunduran hisse senetlerine belirli kriterler doğrultusunda farklı oranlarda yatırım yapılarak en iyi portföyün oluşturulması bir başka adla portföy optimizasyon süreci olarak tanımlanabilmektedir. Portföy optimizasyonunda riskli hisse senetleri arasında tercih yapılırken karar verici olan yatırımcının bakış açısıyla farklı kriterler göz önüne alınabilmektedir. Portföy seçim probleminin özünü optimum portföy bileşimini belirli kriterler altında elde etmek oluşturmaktır. Fakat portföyün temel değerlendirme unsurunu getiri ve risk öğeleri oluşturmaktadır. Markowitz (1952) tarafından ortaya atılan Modern Portföy Teorisine (MPT) göre portföyün ortalaması ve varyansı bu unsurları sırasıyla karşılamaktadır. MPT ile, hisse senetleri getiri serilerinin normal dağıldığı ve karar vericilerin fayda fonksiyonunun kuadratik yapıda olduğu temel varsayımlarına dayanan ortalama-varyans modeli (OVM) önerilmiştir.

OVM odaklı portföy optimizasyonu üzerine çok sayıda çalışma yapılmış ve Steinbach (2001) çalışmasında bu modellere yer vermiştir. Bununla birlikte, ortalama ve varyans, hisse senedi getirilerinin normal dağılmadığı durumlarda en iyi portföyü seçmek için yetersiz olmaktadır. Ayrıca OVM yatırımciların stratejilerini kuadratik fayda fonksiyonu ile kısitlamaktadır (Arditti, 1971: 911; Konno vd., 1993: 94).

Bilgisayar ve yazılım teknolojilerinin gelişimiyle portföy modelleri sadece doğrusal modeller ve küçük boyutlu yapılar çerçevesindeki sınırlarını aşmış ve büyük boyutlu, karmaşık fonksiyonlar barındıran, kuadratik ve doğrusal olmayan programlama yöntemleri ile modellenmeye ve çözülmeye başlanmıştır. Son dönemde yüksek dereceden momentler içeren ortalama-varyans-çarpıklık-basıklık modeli (OVÇBM) portföy seçiminde sıklıkla kullanılmaya başlanmıştır.

Yüksek dereceden moment içeren portföy seçimini konu almış önde gelen bazı çalışmalar, Samuelson (1970), Levy (1974), Arditti ve Levy (1975), Singleton ve Wingender (1986), Konno ve Suzuki (1995), Chunhachinda vd. (1997), Liu vd. (2003), Prakash vd. (2003), Jurczenko vd. (2005), Lai vd. (2006), Maringer ve Parpas (2009), Mhiri ve Prigent (2010), Kemalbay vd. (2011), Aracioğlu vd. (2011), Wang ve Xia (2012) tarafindan yapılmıştır. Portföy optimizasyon sürecine çarpıklığın katılımının yatırımcılara daha yüksek getiri kazandırabileceğine dair bulgulara ulaşılmıştır. Negatif çarpıklık bulunan portföylerde büyük kayıplar az sıklıkla olsa da gözlenebilmekte, pozitif çarpıklıkta ise tam tersi büyük kazanç imkanı doğmaktadır (Harvey, vd., 2010: 470).

Portföy optimizasyonunda kullanılan ortalama, varyans, çarpıklık ya da basıklık gibi fonksiyonlar portföyün doğal çeşitliliğini garanti altına alan yaklaşımlar olmamakta, çoğu zaman portföy seçiminde belirli hisse senetlerine yığılmalara sebep olmaktadırlar. Finansal kriz dönemlerinde iyi çeşitlendirilmiş portföyler daha az riske sahip olmaktadırlar. Portföyde sadece geçmiş verileri kullanarak yapılan çeşitlendirme gelecekteki belirsizliklere göre çeşitlendirmeye izin vermemekte fakat portföy optimizasyonunda entropi fonksiyonunun kullanımı gelecekteki belirsizliği modele ekleyebilmektedir.

Literatürde entropi fonksiyonuyla portföy seçim çalışmalarına bakıldığında, Jana vd. (2007), Bera ve Park (2008), Usta ve Kantar (2011) portföy seçimini yüksek dereceden momentler ve entropi ile gerçekleştirmişlerdir. Zhou vd. (2013) farklı entropi fonksiyonlarını portföy optimizasyonunda kullanan çalışmaları incelemişlerdir. Qin vd. (2009) bulanık çapraz entropiyi genetik algoritma ve bulanık simulasyon ile kullanarak portföy seçimi gerçekleştirmiştir. Huang (2012) oransal bir entropi tanımlayarak bulanık çok amaçlı optimizasyon yaklaşımı ile en uygun portföyü seçmiştir. Joshi ve Kumar (2014) bulanık 
entropi tanımlayarak bulanık TOPSIS ile portföyleri analiz etmişlerdir. Yue ve Wang (2017) OVÇBM'ye entropi fonksiyonu ekleyerek portföy seçim problemine yeni bir çözüm yaklaşımı getirmiş̧lerdir.

Portföy seçim sürecinde birbiri ile çelişen ortalama, varyans, çarpıklık, basıklık ve entropi fonksiyonlarını birlikte optimizasyona dahil etmek için farklı yöntemler mevcuttur. Yöntemlerden biri olan Çok Kriterli Karar Verme (ÇKKV) metodu, kriterlerin çeliştiği durumlarda kullanışlı ve etkin çözümler veren yaklaşımlardır. Portföy seçiminde ÇKKV, Xidonas vd., (2009) çalışmalarında olduğu gibi portföye dahil edilecek hisse senetlerini belirlemede öncül bir analiz olarak kullanılabilirken aynı zamanda Ballestero vd., (2007) çalışmalarında olduğu gibi Pareto portföylerinin sıralanmasında ardıl bir yaklaşım olarak kullanılabilmektedir. Vetschera ve De Almeida (2012) ve Aksaraylı ve Pala (2016) çalışmalarında PROMETHEE ile alternatif portföyleri sıralayarak etkin sonuçlar elde etmişlerdir.

Çalışmada yüksek dereceden momentler ve entropi fonksiyonlarının portföy seçim sürecinde ektinliğini gösterebilmek adına iki aşamalı bir portföy seçim süreci belirlenmiştir. İlk önce OVM'ye göre Pareto etkin sınır elde edilmiş ve sonrasında elde edilen Pareto optimal portföyler, yüksek dereceden momentler ve entropi fonksiyonlarını değerlendirme kriterleri olarak kullanan iki farklı ÇKKV yöntemi TOPSIS ve PROMETHEE ile sıralanmıştır. Sonrasında ÇKKV ile elde edilen portföy sıralamaları, test periyodunda gerçek performansların portföy değerlendirme ölçütleri ile ölçülmesi sonucu ortaya çıkan portföy sıralamaları ile karşılaştırılmıştır.

\section{Yöntemler}

Çalışmanın yöntemler kısmında sırasıyla, optimize edilmek istenen portföy amaçlarına, elde edilen portföylerin performanslarını farklı ve literatürde kabul görmüş yaklaşımlarla ölçen portföy performans ölçütlerine, değerlendirmek istediğimiz Pareto sınırının elde edileceği etkin sınır oluşturan OVM yaklaşımına ve son olarak oluşan Pareto etkin portföyleri belirli portföy amaçları ve yatırımcı tiplerine göre sıralamamıza izin verecek TOPSIS ve PROMETHEE adlı iki ÇKKV metodu yer almaktadır.

\subsection{Portföy Optimizasyon Amaçları}

Portföy optimizasyon sürecinde dikkate alınacak ve optimizasyon sürecine dahil edilecek portföy amaçları belirlenirken yatırımcının fayda fonksiyonu kadar hisse senetlerinin dağılım yapısı da dikkate alınmalıdır. Hisse senetlerinin normal dağılmadığı durumlarda önemli hale gelen yüksek dereceden momentler olan portföy çarpıklık ve basıklığı ile gelecek belirsizlikten daha az etkilenmek için kullanılan ve bir doğal çeşitlilik fonksiyonu olan entropi fonksiyonu, klasik ortalama ve varyans amaç fonksiyonlarına portföy seçim sürecinde eşlik edeceklerdir.

Aşağıda, seçim sürecinde kullanılan beş adet amaç fonksiyonunun elde edilişi bulunmaktadır (Pala ve Aksarayli, 2016: 101);

$$
R_{p e}=E\left(R_{p}\right)=W^{T} M=\sum_{i=1}^{n} w_{i} m_{i}
$$




$$
\begin{gathered}
V_{p}=V\left(R_{p}\right)=W^{T} V(W)=\sum_{i=1}^{n} \sum_{j=1}^{n} w_{i} w_{j} \sigma_{i j} \\
S_{p}=S\left(R_{p}\right)=E\left(W^{T}(R-M)\right)^{3}=W^{T} S(W \otimes W)=\sum_{i=1}^{n} \sum_{j=1}^{n} \sum_{k=1}^{n} w_{i} w_{j} w_{k} s_{i j k} \\
K_{p}=K\left(R_{p}\right)=E\left(W^{T}(R-M)\right)^{4}=W^{T} K(W \otimes W \otimes W)=\sum_{i=1}^{n} \sum_{j=1}^{n} \sum_{k=1}^{n} \sum_{l=1}^{n} w_{i} w_{j} w_{k} w_{l} k_{i j k l} \\
E_{s}=-\sum_{i=1}^{n} w_{i} \ln w_{i}=-W^{T}(\ln W)
\end{gathered}
$$

Eşitlik (1)-(5) deki portföy amaç fonksiyonlarına dair notasyon bilgisi Tablo 1'deki gibi olmuştur.

\section{Tablo 1: Portföy Amaç Fonksiyonları Notasyonu}

\begin{tabular}{|l|l|}
\hline$W$ & hisse senedi ağırlık vektörü \\
\hline$R_{p}$ & portföyün getiri oranı \\
\hline$E\left(R_{p}\right)$ & portföyün beklenen getiri oranı \\
\hline$\sigma_{i j}$ & j. ve i. hisse senetlerinin arasındaki kovaryans \\
\hline$V$ & hisse senetleri varyans kovaryans matrisi \\
\hline$V\left(R_{p}\right)$ & portföyün varyansı \\
\hline$S_{i j k}$ & i., j. ve k. hisse senetlerinin arasındaki çarpıklık parametresi \\
\hline$S$ & hisse senetleri ortak çarpıklık matrisi \\
\hline$S\left(R_{p}\right)$ & portföyün çarpıklığı \\
\hline$k_{i j k l}$ & i., j., k. ve l. hisse senetlerinin arasındaki basıklık parametresi \\
\hline$n$ & portföy seçiminde kullanılan hisse senedi sayısı \\
\hline$w_{i} w_{j} w_{k} w_{l}$ & i., j., k. ve l. hisse senedinin portföydeki oranı \\
\hline$m_{i} m_{j} m_{k} m_{l}$ & i., j., k. ve l. hisse senedinin ortalama getiri oranı \\
\hline$r_{i t}$ & i. hisse senedinin t. periyottaki getiri oranı \\
\hline$R_{i}, R_{j}, R_{k}, R_{l}$ & i., j., k. ve l. hisse senedinin getiri oranı serileri \\
\hline$K$ & hisse senetleri ortak basıklık matrisi \\
\hline$K\left(R_{p}\right)$ & portföyün basıklı̆ı \\
\hline
\end{tabular}




\subsection{Portföy Performans Ölçütleri}

Toplam riski dikkate alan, sistematik riski değerlendiren ve yüksek dereceden momentleri içeren çok çeşitli portföy performans ölçütü bulunmaktadır. Literatürde kabul görmüş ve amaçlarımıza göre seçilen yedi adet portföy performans ölçütü aşağıdaki gibi olmuştur.

\subsubsection{Sharpe Oranı}

Performans değerlendirmede en çok kabul görmüş ve ortalama getirinin standart sapmaya bölümü şeklinde bir birim standart sapmaya karşılık gelen getiri oranını performans ölçütü olarak kullanan Sharpe Oranı (SR) aşağıdaki gibi modellenmektedir (Caporin vd., 2014: 3);

$$
S R=\frac{E\left(R_{p}\right)}{\sqrt{\sigma^{2}\left(R_{p}\right)}}
$$

Daha büyük SR değeri riske göre daha büyük getiriyi ve performansı ifade etmektedir.

\subsubsection{Sortino Oranı}

Sortino Oranı (SoR), SR'den farklı olarak yatırımcıların sadece aşağı yönlü riski önemsediği varsayımı ile paydada standart sapma yerine aşağı yönde sapma kullanmaktadır. Asimetrik getiri dağılımlarına sahip riskli varlıklar için daha iyi bir ölçü birimidir. SoR ortalama getirinin, alt kısmi standart sapmaya oranıdır. Minimum kabul edilebilir değer negatif olmama durumunda SoR aşağıdaki gibi ifade edilebilir (Kaplan ve Knowles, 2004: 45).

$$
S o R=\frac{E\left(R_{p}\right)}{\sqrt{E\left[\max \left(-R_{p}, 0\right)^{2}\right]}}
$$

\subsubsection{Treynor Oranı}

Riskli varlığın pazarla olan ilişkisinden yola çıkarak sistematik risk birim başına ortalama getiriyi ifade eden Treynor Oranı (TO) aşağıdaki gibi hesaplanmaktadır (Hübner, 2005: 417).

$T O=\frac{E\left(R_{p}\right)}{\beta_{p}}$

Riskli varlığın pazarla ilişkisini gösteren $\beta_{p}$ değeri aşağıdaki gibi hesaplanmaktadır.

$$
\beta_{p}=\frac{\operatorname{Cov}\left(R_{p}, R_{m}\right)}{\sigma^{2}\left(R_{m}\right)}
$$

\subsubsection{Jensen Oranı}

Jensen Oranı (JO) ortalama getirinin, riskli varlığın pazarla ilişkisi gösteren $\beta_{p}$ değeri ile pazar ortalama getirisinin çarpım değerinin farkı ile aşağıdaki gibi hesaplanmaktadır (Caporin vd., 2014: 8);

$$
J O=E\left(R_{p}\right)-\beta_{p} E\left(R_{m}\right)
$$




\subsubsection{Değerleme Oranı}

Değerleme oranı (DO), riskli varlığın JO değerini sistematik olmayan riske bir başka adla kendi standart sapmasına bölerek, sistematik ve sistematik olmayan riski beraber dikkate alarak aşağıdaki gibi hesaplanmaktadır.

$$
D O=\frac{J O}{\sqrt{\sigma^{2}\left(R_{p}\right)}}
$$

\subsection{6. Çarpıklık İçin Düzeltilmiş Sharpe Oranı}

Çarpıklık İçin Düzeltilmiş Sharpe Oranı (ASR), SR'nin çarpıklık eklenmiş bir fonksiyonu olarak aşağıdaki gibi hesaplanmaktadır (Zakamouline ve Koekebakker, 2009: 1245),

$$
A S R=S R \sqrt{1+\frac{S k\left(R_{p}\right)}{3} S R}
$$

\subsection{7. Çarpıklık ve Basıklık İçin Düzeltilmiş Sharpe Oranı}

Gerçekleşen performansı, sadece ortalama ve varyansa göre değerlendirmek yerine gerçekleşen getiri serilerinin yüksek moment değerlerini de dikkate alan Pezier ve White (2006) çalışmasında basit ve etkili bir şekilde çarpıklık ve basıklığı performans ölçümüne aşağıdaki gibi Çarpıklık ve Basıklık İçin Düzeltilmiş Sharpe Oranı (ASKR) ile dahil etmiştir. $E k$ ile aşırı basıklık tanımlanmıştır.

$$
A S K R=S R\left(1+\frac{S k\left(R_{p}\right)}{6} S R-\left(\frac{E k}{24}\right) S R^{2}\right)
$$

\subsection{Ortalama Varyans Modeli}

Markowitz'in (1959) tanımladığı OVM'de portföyün getirisi olan beklenen getiri oranı maksimize edilirken, portföyün riski olarak ifade edilen portföyün varyansı minimize edilir. Portföy beklenen getiri oranı ve portföy varyansında hesaplanması gereken hisse senetlerine ait ortalama beklenen getiri, varyans ve kovaryans hesaplamaları sırasıyla aşağıdaki gibidir;

$$
\begin{aligned}
& m_{i}=\frac{1}{T} \sum_{t=1}^{T} r_{i t} \\
& \sigma_{i}^{2}=\frac{1}{T} \sum_{t=1}^{T}\left(r_{i t}-m_{i}\right)^{2} \\
& \sigma_{i j}=\frac{1}{T} \sum_{t=1}^{T}\left(r_{i t}-m_{i}\right)\left(r_{j t}-m_{j}\right)
\end{aligned}
$$

OVM çözümünde çok amaçlı optimizasyondan yararlanarak etkin sınır ve Pareto çözümler elde edilebileceği gibi, yatırımcının spesifik hedef ve kararları doğrultusunda model değiştirilebilir. OVM'de belirli bir beklenen getiri oranı ya da ortalama oranı (OO) için risk 
minimizasyonu şeklinde aşağıdaki gibi ifade edilebilir. Bu modelden çözüm elde edilmesi karesel optimizasyon yöntemleri ile nispeten daha kolaydır (Wang ve Xia, 2002: 4).

$$
\left\{\begin{array}{cc}
\text { Min } & W^{T} V(W) \\
k s t & W^{T} M \geq O O \\
& W^{T} 1_{N}=1 \\
& W \geq 0
\end{array}\right.
$$

Burada nx1 boyutunda 1'lerden oluşan sütun vektörü $1_{N}$ ile ifade edilmektedir. OVM ayrıca belirli bir risk oranı ya da varyans oranı (VO) için getiri maksimizasyonu şeklinde aşağıdaki gibi ifade edilebilir. Doğrusal olmayan kısıtlama nedeniyle çözüm elde etmek daha zordur (Ehrgott vd., 2009: 33).

$$
\left\{\begin{array}{c}
\text { Maks } \quad W^{T} M \\
k s t ; \quad W^{T} V(W) \leq V O \\
W^{T} 1_{N}=1 \\
W \geq 0
\end{array}\right.
$$

Ayrıca farklı $\lambda$ değerleri için çözülen eşitlik ile portföy etkin sınırı elde edilebilmektedir. Maksimum getiri modeli $\lambda=0$ için problem çözüldüğünde, minimum varyans modeli $\lambda=1$ için çözüm yapıldığında elde edilmektedir. Buna göre $0 \leq \lambda \leq 1$ aralığındaki çözümler ile Pareto optimal çözümler aşağıdaki eşitlik 19 ile elde edilir (Demirtaş ve Güngör, 2004: 105).

$$
\left\{\begin{array}{c}
\operatorname{Min} \lambda\left[W^{T} V(W)\right]-(1-\lambda)\left[W^{T} M\right] \\
k s t ; \\
W^{T} 1_{N}=1 \\
W \geq 0
\end{array}\right.
$$

Yatırımcının farklı ağırlık parametrelerine göre eşitlik çözüldüğünde OVM için etkin sınır Şekil 1'deki gibi elde edilir. Bu sınır üzerindeki tüm portföyler yatırımcı açısından ortalama ve varyans değerleri için ön değerlendirme ve tercih bulunmadığ 1 takdirde Pareto optimaldir. Etkin sınır portföyleri yatırımcıya belirli risk değeri için maksimum getiri veya diğer bir tanımlama ile belirli getiri değeri için minimum risk sağlar (Markowitz, 1959: 141).

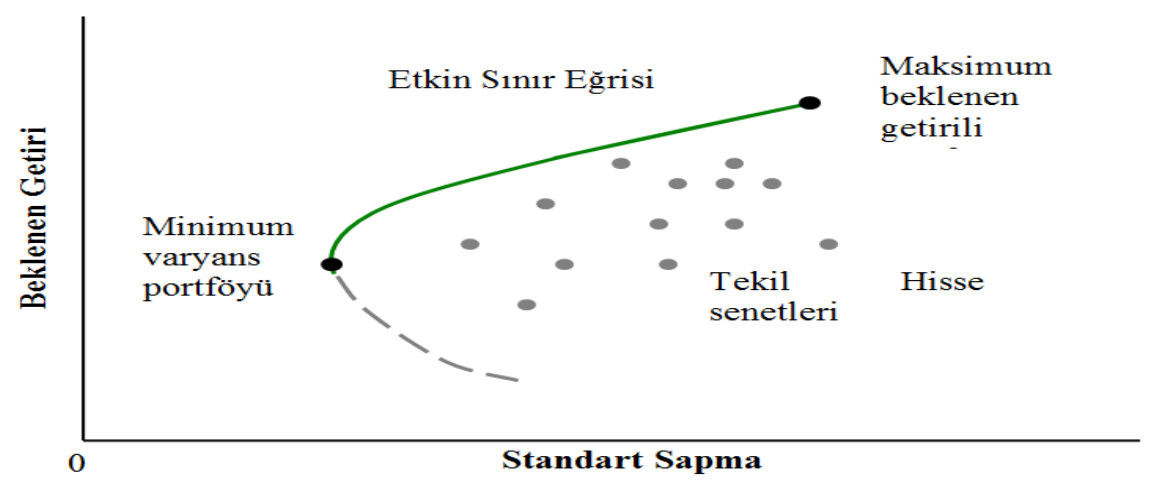

Şekil 1. Ortalama Varyans Etkin Sınır. Kaynak: (Chen vd., 2010: 9). 
Elde edilen Pareto optimal çözümlerden herhangi birini karar verici kendi fayda fonksiyonu ve tercihlerine göre seçebilir.

\subsection{TOPSIS Yaklaşımı}

Yoon ve Hwang tarafindan 1981 yilında TOPSIS (Technique for Order Preference by Similarity to Ideal Solution) adıyla önerilen metot karar noktalarının ideal çözüme yakınlığı ana prensibine dayanmaktadır. Behzadian vd., (2012) TOPSIS ile yapılmış çalışmaları ve kullanım alanlarını detaylı bir şekilde incelemişlerdir. Aşağıda TOPSIS yönteminin adımları tanımlanmıştır (Opricovic ve Tzeng, 2004: 448; Yaralığlu, 2004: 17-20);

\section{Adım 1 : Karar Matrisi A'nın Elde Edilişi}

Karar matrisinin satırlarında alternatifler, sütunlarında ise kriterler yer almaktadır. A matrisi karar verici tarafından objektif ve sübjektif değerlendirmeler sonucu oluşturulur. $A_{i j}$ matrisinde m alternatif sayısını, $n$ kriter sayısını vermektedir. Karar matrisi aşağıdaki gibi gösterilir:

$$
A_{i j}=\left[\begin{array}{cccc}
a_{11} & a_{12} & \ldots & a_{1 n} \\
a_{21} & a_{22} & \ldots & a_{2 n} \\
\cdot & & & \cdot \\
\cdot & & & \cdot \\
\cdot & & & \cdot \\
a_{m 1} & a_{m 2} & \ldots & a_{m n}
\end{array}\right]
$$

Adım 2 : Standart Karar Matrisi R'nin Elde Edilişi

$\mathrm{R}$ matrisi elemanları, A matrisinin elemanlarından aşağıdaki gibi hesaplanmaktadır.

$$
r_{i j}=\frac{a_{i j}}{\sqrt{\sum_{i=1}^{m} a_{i j}^{2}}}
$$

$\mathrm{R}$ matrisi ise aşağıdaki gibi elde edilir:

$$
R_{i j}=\left[\begin{array}{cccc}
r_{11} & r_{12} & \ldots & r_{1 n} \\
r_{21} & r_{22} & \ldots & r_{2 n} \\
\cdot & & & \cdot \\
\cdot & & & \cdot \\
\cdot & & & \cdot \\
r_{m 1} & r_{m 2} & \ldots & r_{m n}
\end{array}\right]
$$




\section{Adım 3 : Ağırlıklı Standart Karar Matrisi V’nin Elde Ediliş̧i}

Öncelikle kriterlere ilişkin ağırlık değerleri $\left(w_{i}\right)$ toplamları 1 olacak şekilde karar verici tarafindan belirlenmelidir. Daha sonra R matrisinin her bir sütunundaki elemanlar karşıllık gelen $w_{i}$ değeri ile çarpılarak V matrisi oluşturulur. V matrisi aşağıdaki gibidir:

$$
V_{i j}=\left[\begin{array}{cccc}
w_{1} r_{11} & w_{2} r_{12} & \ldots & w_{n} r_{1 n} \\
w_{1} r_{21} & w_{2} r_{22} & \ldots & w_{n} r_{2 n} \\
\cdot & & & \cdot \\
\cdot & & & \cdot \\
\cdot & & & \cdot \\
w_{1} r_{m 1} & w_{2} r_{m 2} & \ldots & w_{n} r_{m n}
\end{array}\right]
$$

Adım 4 : Pozitif İdeal $A^{+}$ve Negatif İdeal $A^{-}$Çözüm Değerlerinin Elde Edilişi

TOPSIS yöntemi, her bir kriterin monoton artan veya azalan bir eğilime sahip olduğunu varsaymaktadır. İdeal çözüm setinin oluşturulabilmesi için V matrisindeki ağırlıklandırılmış kriterlerin en büyükleri (ilgili kriter minimizasyon yönlü ise en küçüğü) seçilir. Pozitif ideal çözüm setinin bulunması aşağıdaki formülde gösterilmiştir.

$$
A^{+}=\left\{\left(\max _{i} v_{i j} \mid j \in J\right),\left(\min _{i} v_{i j} \mid j \in J^{\prime}\right\}\right.
$$

Hesaplanacak elemanlar, $A^{+}=\left\{v_{1}^{*}, v_{2}^{*}, \ldots, v_{n}^{*}\right\}$ şeklinde gösterilebilir.

Negatif ideal çözüm seti ise, V matrisindeki ağırlıklandırılmış kriterlerin en küçükleri (ilgili kriter maksimizasyon yönlü ise en büyüğü) seçilerek oluşturulur. Negatif ideal çözüm setinin hesaplanması aşağıdaki gibidir.

$$
A^{-}=\left\{\min _{i} v_{i j} \mid j \in J\right),\left(\max _{i} v_{i j} \mid j \in J^{\prime}\right\}
$$

Hesaplanacak elemanlar, $A^{-}=\left\{v_{1}^{-}, v_{2}^{-}, \ldots, v_{n}^{-}\right\}$şeklinde gösterilebilir. Pozitif ve negatif ideal çözüm değerleri için $J$ fayda (maksimizasyon), $J^{\prime}$ ise kayıp (minimizasyon) değerini ifade etmektedir.

\section{Adım 5 : Ayırım Ölçülerinin Hesaplanması}

TOPSIS yönteminde her bir alternatife ilişkin kriter değerinin pozitif ideal ve negatif ideal çözüm setinden sapmalarının bulunabilmesi için öklid uzaklık değeri kullanılmaktadır. Buradan elde edilen alternatiflere ilişkin sapma değerleri ise pozitif ideal ayırım $\left(S_{i}^{+}\right)$ve negatif ideal ayırım $\left(S_{i}^{-}\right)$ölçüsü olarak adlandırılmaktadır. Pozitif ideal ayırım $\left(S_{i}^{+}\right)$ ölçüsünün ve negatif ideal ayırım ( $S_{i}^{-}$) ölçüsünün hesaplanması sırasıyla aşağıdaki gibidir,

$$
S_{i}^{+}=\sqrt{\sum_{j=1}^{n}\left(v_{i j}-v_{j}^{*}\right)^{2}} \quad S_{i}^{-}=\sqrt{\sum_{j=1}^{n}\left(v_{i j}-v_{j}^{-}\right)^{2}}
$$


Hesaplanacak $S_{i}^{+}$ve $S_{i}^{-}$sayıs1 alternatif adeti kadar olacaktır.

\section{Adım 6 : İdeal Çözüme Göreli Yakınlığın Hesaplanması}

Her bir alternatifin ideal çözüme göreli yakınlığının $\left(C_{i}^{*}\right)$ hesaplanmasında pozitif ideal ve negatif ideal ayırım ölçülerinden yararlanılır. Burada kullanılan ölçüt, negatif ideal ayırım ölçüsünün toplam ayırım ölçüsü içindeki oranıdır. İdeal çözüme göreli yakınlık değerinin hesaplanması aşağıdaki gibidir.

$$
C_{i}^{*}=\frac{S_{i}^{-}}{S_{i}^{-}+S_{i}^{+}}
$$

$C_{i}^{*}$ değeri $0 \leq C_{i}^{*} \leq 1$ aralığında değer alır ve $C_{i}^{*}=1$ ilgili alternatifin ideal çözüme, $C_{i}^{*}=0$ ilgili alternatifin negatif ideal çözüme mutlak yakınlığını gösterir. Alternatifler seçim için ideal çözüme yakınlık değer büyüklüğüne göre büyükten küçüğe sıralanır. Göreli yakınlık değerleri standartlaştırılarak alternatif önem dereceleri elde edilebilmektedir.

\subsection{PROMETHEE Yaklaşımı}

Brans (1982) ve Brans ve Vincke (1985) "Preference Ranking Organization Method for Encrichment Evaluations" (PROMETHEE) yöntemini ÇKKV problemlerinde alternatifleri sıralama yaklaşımı olarak önermişlerdir. PROMETHEE I ve II sırasıyla kısmi ve tam sıralama modelleridir. Sonlu sayıda alternatifi belirli kriterlere göre sıralayan ve kritelere ait tercih fonksiyon ve ağırlıkları karar verici tarafindan tanımlanan bir ÇKKV yöntemidir (Macharis vd., 2004: 308). Tablo 2'de PROMETHEE'nin genel yapısı bulunmaktadır.

Tablo 2: PROMETHEE Değerlendirme Yapısı

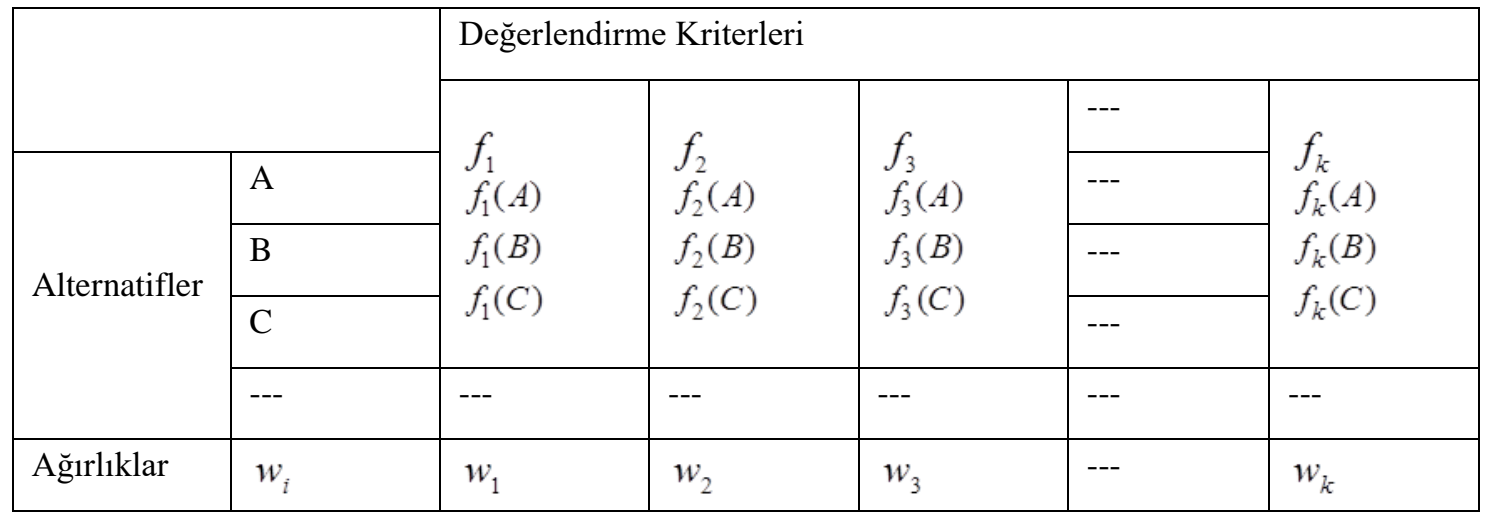

PROMETHEE metotu altı adet, çoğu zaman kriterleri değerlendirmeye yeterli olan tercih fonksiyonlarına sahiptir (Brans vd., 1986: 229-231). Tablo 3'de PROMETHEE tercih fonksiyonları ve fonksiyonlarda bulunan parametreler yer almaktadır.

Parametrelerin tanımları aşağıdaki gibidir.

$q$ : Farksızlık tercih eşiği

$p:$ Kesin tercih eşiği

d: Faktörler arası fark değeri. 
Tablo 3'deki fonksiyon yapılarından anlaşılacağı üzere, sadece tercih fonksiyonu değil $p$ ve $q$ parametre değerlerinin seçimi de önemli bir husustur. Kesin tercih eşiği $p$, ilgili kritere ait en iyi değere sahip alternatife göre belirlenebilir. Farksızlık tercih eşiği $q$, normalize edilmiş veriler için belirli bir değere göre seçilebilir. Çalışmada, sayısal veriler için sıklıkla kullanılan tip 5 doğrusal tercih fonksiyonu her bir kritere uyarlanmıştır. Parametreler $p$ optimum değer, $q$ ise 0.20 olarak seçilmiştir.

Tablo 3: PROMETHEE Tercih Fonksiyonları

\begin{tabular}{|c|c|c|c|c|c|}
\hline & Fonksiyon & Parametre & & Fonksiyon & Parametre \\
\hline $\begin{array}{l}\text { Tip I } \\
\text { (Olağan) }\end{array}$ & $P(d)= \begin{cases}0 & d \leq 0 \\
1 & d>0\end{cases}$ & --- & $\begin{array}{l}\text { Tip IV } \\
\text { (Seviyeli) }\end{array}$ & $P(d)=\left\{\begin{array}{cc}0 & d \leq q \\
\frac{1}{2} & q<d \leq p \\
1 & d>p\end{array}\right.$ & $p, q$ \\
\hline $\begin{array}{l}\text { Tip II } \\
\text { (U tipi) }\end{array}$ & $P(d)= \begin{cases}0 & d \leq q \\
1 & d>q\end{cases}$ & $q$ & $\begin{array}{l}\text { Tip V } \\
\text { (Doğrusal) }\end{array}$ & $P(d)=\left\{\begin{array}{cc}0 & d \leq q \\
\frac{d-q}{p-q} & q<d \leq p \\
1 & d>p\end{array}\right.$ & $p, q$ \\
\hline $\begin{array}{l}\text { Tip III } \\
\text { (V tipi) }\end{array}$ & $P(d)=\left\{\begin{array}{cc}0 & d \leq 0 \\
\frac{d}{p} & 0<d \leq p \\
1 & d>p\end{array}\right.$ & $p$ & $\begin{array}{l}\text { Tip VI } \\
\text { (Gaussian) }\end{array}$ & $P(d)=\left\{\begin{array}{cc}0 & d \leq 0 \\
1-e^{-\frac{d^{2}}{2 s^{2}}} & d>0\end{array}\right.$ & $S$ \\
\hline
\end{tabular}

Tercih fonksiyon ve parametre seçimi sonrası ikili karşılaştırmalar aşağıdaki gibi yapılabilir,

$$
P(A, B)=\left\{\begin{array}{cc}
0 & f(A) \leq f(B) \\
p[f(A)-f(B)] & f(A)>f(B)
\end{array}\right.
$$

A ve B alternatifler olmak üzere ikili karşılaştırma sonucu A'nın B'ye tercih indeksini aşağıdaki gibi tanımlayabiliriz,

$$
\pi(A, B)=\sum_{i=1}^{k} w_{i} P_{i}(A, B)
$$

A için pozitif ve negatif akışı, $x$ tüm alternatifleri temsil ederken sırasıyla aşağıdaki gibi elde ederiz,

$$
\Phi^{+}=\frac{1}{n-1} \sum \pi(A, x) \quad \Phi^{-}=\frac{1}{n-1} \sum \pi(x, A)
$$

Tam sıralama için kullanılan net sıralama akışı aşağıdaki eşitlik ile bulunur,

$$
\Phi(A)=\Phi^{+}(A)-\Phi^{-}(A)
$$

Daha büyük net akış değerine sahip alternatif daha üst sıralarda yer alır. 


\section{Uygulama}

Önerilen portföy optimizasyon modellerinin etkinliğini test etmek için kullanılan veri seti, Borsa İstanbul 30 (BIST 30) endeksinde Ocak 2005 - Aralık 2014 tarihleri arasında sürekli işlem görmüş 21 adet hisse senedinin aylık getiri serilerinden oluşmaktadır. Veriler BISST'in internet sitesinden alınmıştır. Çalışmada kullanılan yöntemler sonucu elde edilen portföylerin getirilerini hesaplamak için kullanılan test periyodu ise Ocak 2015 ile Aralık 2015 dönemlerini kapsamaktadır. Tüm verilere kar payları ve sermaye bölünmeleri eklenerek düzeltilmiştir. Veri setinde bulunan hisse senetlerine ait getiri serilerinin istatistik değerleri ve Jarque-Bera (JB) normallik testi sonuçları Tablo 4'deki gibidir. İstatistik değerler ve JB test sonuçları yüksek dereceden momentlerin portföy seçiminde kullanımını desteklemektedir. JB test sonuçlarından elde edilen $\mathrm{P}$ değerleri önem derecesi altı hisse senedi için $\% 5$ in altında çıkmıştır. Bu da ilgili hisse senetlerinin getiri serilerinin normal dağılmadığını göstermektedir.

Tablo 4: Veri Setinin Özet İstatistikleri

\begin{tabular}{|c|c|c|c|c|c|c|}
\hline & Ortalama & Varyans & Çarpıklık & Basıklık & JB & $\mathrm{P}$ \\
\hline $\mathrm{X} 1$ & 0.0165 & 0.0141 & 0.7785 & 5.1201 & 34.5946 & 0.001 \\
\hline $\mathrm{X} 2$ & 0.0194 & 0.0169 & 0.3149 & 4.5095 & 13.3754 & 0.0084 \\
\hline $\mathrm{X} 3$ & 0.03 & 0.0226 & -0.2585 & 2.9195 & 1.3692 & 0.4308 \\
\hline $\mathrm{X} 4$ & 0.007 & 0.0142 & 0.3944 & 3.5317 & 4.5241 & 0.0724 \\
\hline X5 & 0.0204 & 0.0113 & -0.4709 & 3.3511 & 5.0504 & 0.0585 \\
\hline X6 & 0.0241 & 0.0129 & -0.1355 & 2.8527 & 0.4756 & 0.5 \\
\hline $\mathrm{X} 7$ & 0.0241 & 0.0096 & -0.1028 & 3.2567 & 0.5406 & 0.5 \\
\hline $\mathrm{X} 8$ & 0.0238 & 0.0149 & 0.4029 & 3.4497 & 4.2579 & 0.0808 \\
\hline X9 & 0.0156 & 0.0124 & 0.3306 & 2.8495 & 2.2988 & 0.237 \\
\hline X10 & 0.0198 & 0.0138 & 0.2601 & 3.4043 & 2.1706 & 0.2594 \\
\hline X11 & 0.0249 & 0.0158 & -0.1602 & 3.1383 & 0.6087 & 0.5 \\
\hline $\mathrm{X} 12$ & 0.0371 & 0.0186 & 0.3552 & 4.4525 & 13.0732 & 0.0088 \\
\hline $\mathrm{X} 13$ & 0.0154 & 0.0116 & -0.1574 & 4.3546 & 9.671 & 0.0171 \\
\hline X14 & 0.0178 & 0.0149 & 0.5956 & 4.1968 & 14.2554 & 0.0073 \\
\hline X15 & 0.0181 & 0.0132 & 0.0369 & 2.7713 & 0.2888 & 0.5 \\
\hline X16 & 0.0124 & 0.0071 & -0.0638 & 3.856 & 3.7455 & 0.1017 \\
\hline X17 & 0.0273 & 0.0157 & 0.1254 & 2.7353 & 0.6649 & 0.5 \\
\hline X18 & 0.0288 & 0.0181 & -0.2094 & 4.3635 & 10.1733 & 0.0154 \\
\hline X19 & 0.0238 & 0.009 & -0.2218 & 2.7245 & 1.3635 & 0.4325 \\
\hline $\mathrm{X} 20$ & 0.0208 & 0.0132 & 0.1148 & 3.8213 & 3.6361 & 0.1075 \\
\hline $\mathrm{X} 21$ & 0.0174 & 0.0146 & 0.3827 & 3.5507 & 4.4459 & 0.0748 \\
\hline
\end{tabular}

Çalışmada OVM ile eşitlik 6'yı kullanarak 181 adet Pareto portföy elde edilmiştir. Pareto portföylerin portföy amaç fonksiyonları açısından en büyük, en küçük ve ortalama değerleri Tablo 5'deki gibi gerçekleşmiştir.

\section{Tablo 5: Pareto Portföylerin En İyi, Kötü ve Ortalama Değerleri}

\begin{tabular}{l|lllll} 
Pareto & Ortalama & Varyans & Çarpıklık & Basıklık & Entropi \\
\hline En İyi & 0.036 & 0.0047 & 0.0003 & 0.0001 & 1.8517 \\
En Kötü & 0.0181 & 0.0161 & -0.0004 & 0.0011 & 0.4817 \\
Ortalama & 0.027 & 0.0078 & -0.0002 & 0.0003 & 1.521 \\
\hline
\end{tabular}


Yatırımc tipleri için agresif, normal ve defansif modeller PROMETHEE ve TOPSIS ile oluşturulmuştur. Kriterler olarak ortalama, varyans, çarpıklık, basıklık ve entropi değerleri baz alınmıştır. Agresif modeller olan PROMETHEEa ve TOPSISa'da ortalama ve çarpıklık amaç fonksiyonlarının ağırlıkları diğerlerine göre 3 kat fazla iken, defansif modeller olan PROMETHEEd ve TOPSISd'de varyans, basıklık ve entropi ağırlıkları 3 kat fazla belirlenmiş, normal modeller olan PROMETHEEn ve TOPSISn'de ise amaç fonksiyonlarının ağırlıkları bir başka adla kriter önem değerleri eşit alınmıştır. Bu durumda toplam altı ÇKKV modeline göre Pareto sıralaması ve önem değerleri elde edilmiştir. Hangi siralamanın daha etkin olduğunu incelemek adına test periyodunda portföylerin performans1 yedi adet portföy performans ölçütü ile ölçülmüştür. Pareto portföylerin portföy performans ölçüt değerleri açısından en büyük, en küçük ve ortalama değerleri ile portföy karşılaştırmada sıklıkla kullanılan eşit ağırlık model (EAM) ölçüt değer sonuçları Tablo 6'daki gibi gerçekleşmiştir. Sonuçlara bakıldığında en kötü Pareto portföy performans değeri EAM'dan daha yüksek performans gerçekleştirerek, elde edilmiş Pareto portföylerin etkinliğini göstermiştir.

Tablo 6: Portföy Performans Ölçütleri En İyi, Kötü ve Ortalama Değerleri

\begin{tabular}{l|lllllll}
\hline & SR & SOR & ASR & ASKR & TO & JO & DO \\
\cline { 2 - 7 } En İyi & 0.1224 & 0.1824 & 0.1216 & 0.1209 & 0.0177 & 0.0099 & 0.1693 \\
En Kötü & -0.1385 & -0.1825 & -0.1379 & -0.1373 & -0.0074 & 0.0004 & 0.0077 \\
Ortalama & -0.0362 & -0.0471 & -0.0362 & -0.0362 & -0.0012 & 0.0041 & 0.0994 \\
EAM & -0.1891 & -0.2503 & -0.1853 & -0.1817 & -0.0079 & 0 & 0 \\
\hline
\end{tabular}

ÇKKV yaklaşımlarından elde edilen önem değerleri ile performans ölçüt skorları Spearman Sıra Korelasyon Testine tabi tutularak aralarında bir ilişki olup olmadığı araştırılmıştır. Tablo 7'deki sonuçlara bakıldığında test değerlerine göre ilişki bulunmuştur. Genel olarak PROMETHEEa gerçek performansa göre sıralamayı en yakın elde eden model olmuştur.

Tablo 7: Spearman Sira Korelasyon Test Sonuçları

\begin{tabular}{|l|l|l|l|l|l|l|}
\hline & TOPSISn & TOPSISa & TOPSISd & PROMETHEEn & PROMETHEEa & PROMETHEEd \\
\hline SR & -0.9773 & -0.3 & -0.9851 & -0.325 & 0.8552 & -0.829 \\
\hline SOR & -0.9771 & -0.3 & -0.9849 & -0.3245 & 0.8554 & -0.8288 \\
\hline ASR & -0.9773 & -0.3 & -0.9851 & -0.325 & 0.8552 & -0.829 \\
\hline ASKR & -0.9773 & -0.3 & -0.9851 & -0.325 & 0.8552 & -0.829 \\
\hline TO & -0.9783 & -0.299 & -0.9859 & -0.3271 & 0.8539 & -0.8298 \\
\hline JO & -0.9733 & -0.302 & -0.9815 & -0.3153 & 0.8592 & -0.8254 \\
\hline DO & -0.8595 & -0.4135 & -0.8844 & -0.0916 & 0.9374 & -0.7257 \\
\hline
\end{tabular}

Tüm sıralamalara göre Portföy no 181, 180 ve 179 sirasıyla tüm performans ölçütlerinde 1., 2. ve 3. sıralarda yer almıştır. TOPSISa ve PROMETHEEa modellerinde de aynı sıralama mevcuttur. PROMETHEEn ve PROMETHEEd modellerinde ilk üçte yer alan portföyler TOPSISn ve TOPSISd'ye göre daha iyi performans göstermiş ve gerçek performans sıralamalarında daha üstte kendilerine yer bulmuşlardır.

En kötü performans1 tüm portföy değerlendirme ölçütlerine göre portföy no 1,2 ve 3 göstermişlerdir. PROMETHEEa kötü performansları tespit etmede çok etkili olmuş ve 
TOPSISa'ya göre çok daha yakın en kötü Pareto portföyleri tespit edip sıralamıştır. PROMETHEEn ve PROMETHEEd ile TOPSISn ve TOPSISd arasında en kötüleri tespit etmede çok önemli farklar bulunmamakla birlikte dört model de iyi performans gösterememiştir.

Genel olarak, Pareto sıralamalarına bakıldığında PROMETHEE sıralamalarının TOPSIS sıralamalarına üstünlüğü göze çarpmaktadır. Yatırımcının genel beklentisi piyasayla uyuştuğunda, PROMETHEE'nin yüksek dereceli momentler ve entropiyi verimli kullanarak, etkin çözümler elde edebildiği gözlenmiştir.

\section{Sonuç}

Portföy seçiminde karar verici durumunda olan yatırımcılar veya finans kuruluşları, portföy seçiminde bulunurken dönemsel sapması çok olmayacak ve belirli düzeyde getiri sağlayacak portföyleri tercih etmektedirler. Bu sayede para akışları ve sermaye yapıları daha sağlıklı olmaktadır. Portföy seçim konusunda doğru ve kapsayıcı analizler, yatırımın etkin ve doğru olma olasılığını arttırmaktadır. Fakat portföyün getirisi ve riski, OVM modelinde olduğu gibi genellikle sadece portföy ortalaması ve varyansı ile tanımlanmaktadır. Hisse senetlerinin getiri serilerinin normal dağılmadığı durumlarda, yüksek dereceden momentlerin kullanımı portföy seçim sürecine daha fazla hisse senetlerine dair dağılım bilgisi katmaktadır. Doğal çeşitliliği sağlayan entropi fonksiyonu ile gelecek belirsizlikten kaynaklı uğranılacak zarar ise özellikle finansal kriz dönemlerinde azalmaktadır.

Çok sayıda kriteri göz önüne alarak doğru seçimi yapmak için etkin bir yaklaşım karar vericiye sunulmalıdır. $\mathrm{Bu}$ amaçla elde edilen Pareto alternatifleri ve sonrasında yatırımcı kararının dahil edildiği ÇKKV yaklaşımı karar verici ile etkileşimli bir yöntem olması açısından önemlidir. Elde edilen portföy seçim sonuçlarının test edilmesi gerekli ve yaklaşıma değer katan bir husustur. Çalışmada PROMETHEEa ile yapılan sıralama gerçek performansa oldukça yakın sonuçlar vererek çalışmanın bakış açısının doğruluğunu ve tutarlılı̆̆ını sağlamıştır.

Gelecek çalışmalarda, farklı portföy seçim modelleri ve kriterleri ile yeni yaklaşımlardan faydalanılarak ortaya etkin ve verimli çözümler çıkacağı öngörülmektedir. 


\section{KAYNAKÇA}

AKSARAYLI, M. ve PALA, O., (2016). A Hybrid Multi-objective Optimization Approach Based on Promethee for Portfolio Selection 2016 Socio-Economic Strategies in Turkey. s:90-108.

ARACIOGLU, B., DEMIRCAN, F. ve SOYUER, H. (2011). Mean-Variance-SkewnessKurtosis Approach to Portfolio Optimization: An Application in Istanbul Stock Exchange/Portföy Optimizasyonunda Ortalama-Varyans-ÇarpiklikBasiklikYaklasimi: IMKB Uygulamasi. Ege Akademik Bakis, 11, 9-17.

ARDITTI, F. D. (1971). Another Look At Mutual Fund Performance. Journal Of Financial And Quantitative Analysis, 6(03), 909-912.

ARDITTI, F. D., ve LEVY, H. (1975). Portfolio Efficiency Analysis In Three Moments: The Multiperiod Case. The Journal Of Finance, 30(3), 797-809.

BALLESTERO, E., GÜNTHER, M., PLA-SANTAMARIA, D., ve STUMMER, C. (2007). Portfolio Selection Under Strict Uncertainty: A Multi-Criteria Methodology And Its Application To The Frankfurt And Vienna Stock Exchanges. European Journal Of Operational Research, 181(3), 1476-1487.

BEHZADIAN, M., OTAGHSARA, S. K., YAZDANI, M., ve IGNATIUS, J. (2012). A state-of the-art survey of TOPSIS applications. Expert Systems with Applications, 39(17), 13051-13069.

BERA, A. K., ve PARK, S. Y. (2008). Optimal Portfolio Diversification Using The Maximum Entropy Principle. Econometric Reviews, 27(4-6), 484-512.

BIST web site. Available online:https://datastore.borsaistanbul.com/ (accessed on 17 September 2017).

BRANS, J. P. (1982). L'ingénieurie de la décision-Elaboration d'instruments d'aidea la décision. La méthode Prométhée-Dans Nadeau R. et Landry M. L'aide à la décision: nature, intruments et perspectives d'avenir-Québec, Canada, 182-213.

BRANS, J. P., ve VINCKE, P. (1985). Note-A Preference Ranking Organisation Method: (The PROMETHEE Method for Multiple Criteria Decision-Making). Management science, 31(6), 647-656.

BRANS, J. P., VINCKE, P., ve MARESCHAL, B. (1986). How to select and how to rank projects: The PROMETHEE method. European journal of operational research, 24(2), 228-238.

CAPORIN, M., JANNIN, G. M., LISI, F., ve MAILLET, B. B. (2014). A Survey On The Four Families Of Performance Measures. Journal Of Economic Surveys, 28(5), $917-$ 942.

CHEN, W. P., CHUNG, H., HO, K. Y., ve HSU, T. L. (2010). Portfolio Optimization Models And Mean-Variance Spanning Tests. In Handbook Of Quantitative Finance And Risk Management (s: 165-184). Springer US.

CHUNHACHINDA, P., DANDAPANI, K., HAMID, S., ve PRAKASH, A. J. (1997). Portfolio Selection And Skewness: Evidence From International Stock Markets. Journal Of Banking \& Finance, 21(2), 143-167. 
DEMIRTAŞ, Ö. ve GÜNGÖR, Z. (2004). Portföy Yönetimi Ve Portföy Seçimine Yönelik Uygulama. Journal Of Aeronautics And Space Technologies, 1(4), 103-109.

EHRGOTT, M., WATERS, C., KASIMBEYLI, R., ve ÜSTÜN, O. (2009). Multiobjective Programming and Multiattribute Utility Functions in Portfolio Optimization. INFOR: Information Systems and Operational Research, 47(1), 31-42. https://doi.org/10.3138/infor.47.1.31

HARVEY, C. R., LIECHTY, J. C., LIECHTY, M. W., ve MÜLLER, P. (2010). Portfolio selection with higher moments. Quantitative Finance, 10(5), 469-485.

HUANG, X. (2012). An entropy method for diversified fuzzy portfolio selection. International Journal of Fuzzy Systems, 14(1), 160-165.

HÜBNER, G. (2005). The generalized Treynor ratio. Review of Finance, 9(3), 415-435.

HWANG, C. L., ve YOON, K. (1981). Multiple Attribute Decision Making, vol. 186 of. Lecture Notes in Economics and Mathematical Systems.

JANA, P., ROY, T. K., ve MAZUMDER, S. K. (2007). Multi-objective mean-varianceskewness model for portfolio optimization. Advanced Modeling and Optimization, 9(1), 181-193.

JOSHI, D., ve KUMAR, S. (2014). Intuitionistic Fuzzy Entropy And Distance Measure Based TOPSIS Method For Multi-Criteria Decision Making. Egyptian Informatics Journal, 15(2), 97-104.

JURCZENKO, E., MAILLET, B. B., ve MERLIN, P. (2005). Hedge funds portfolio selection with higher-order moments: a non-parametric mean-variance-skewnesskurtosis efficient frontier. Available at SSRN 676904.

KAPLAN, P. D., ve KNOWLES, J. A. (2004). Kappa: A Generalized Downside RiskAdjusted Performance Measure. Journal Of Performance Measurement., 8, 42-54.

KEMALBAY, G., ÖZKUT, C. M., ve FRANKO, C. (2011). Portfolio Selection With Higher Moments: A Polynomial Goal Programming Approach To ISE-30 Index. Ekonometri Ve Istatistik Dergisi, (13), 41-61.

KONNO, H., SHIRAKAWA, H., ve YAMAZAKI, H. (1993). A Mean-Absolute DeviationSkewness Portfolio Optimization Model. Annals Of Operations Research, 45(1), 205-220.

KONNO, H., ve SUZUKI, K. I. (1995). A mean-variance-skewness portfolio optimization model. Journal of the Operations Research Society of Japan, 38(2), 173-187.

LAI, K. K., YU, L., ve WANG, S. (2006, June). Mean-variance-skewness-kurtosis-based portfolio optimization. In Computer and Computational Sciences, 2006. IMSCCS'06. First International Multi-Symposiums on (Vol. 2, pp. 292-297). IEEE.

LEVY, H. (1974). The rationale of the mean-standard deviation analysis: Comment. The American Economic Review, 64(3), 434-441.

LIU, S. Y. W. S., WANG, S. Y., ve QIU, W. (2003). Mean-Variance-Skewness Model For Portfolio Selection With Transaction Costs. International Journal Of Systems Science, 34(4), 255-262.

MACHARIS, C., SPRINGAEL, J., DE BRUCKER, K., ve VERBEKE, A. (2004). PROMETHEE and AHP: The Design Of Operational Synergies In Multicriteria 
Analysis.: Strengthening PROMETHEE with ideas of AHP. European Journal of Operational Research, 153(2), 307-317.

MARINGER, D., ve PARPAS, P. (2009). Global Optimization Of Higher Order Moments In Portfolio Selection. Journal Of Global Optimization, 43(2-3), 219-230.

MARKOWITZ, H. (1952). Portfolio selection. The journal of finance, 7(1), 77-91.

MARKOWITZ, H. (1959). Portfolio Selection, Efficient Diversification of Investments. J. Wiley.

MARKOWITZ, H. M. (1991). Foundations Of Portfolio Theory. The Journal Of Finance, 46(2), 469-477.

MHIRI, M., ve PRIGENT, J. L. (2010). International portfolio optimization with higher moments. International Journal of Economics and Finance, 2(5), 157-169.

OPRICOVIC, S., ve TZENG, G. H. (2004). Compromise solution by MCDM methods: A comparative analysis of VIKOR and TOPSIS. European journal of operational research, 156(2), 445-455.

PALA, O., ve AKSARAYLI, M. (2016). Bulanik Hedef Programlama Tabanli Yüksek Dereceden Momentlerle Bist 30 Endeksinde Portföy Seçimi. Sosyal Bilimler Metinleri Dergisi. (ICOMEP16, Özel Say1) 98-113.

PEZIER, J.,ve WHITE, A. (2006). The Relative Merits Of Investable Hedge Fund Indices And Of Funds Of Hedge Funds In Optimal Passive Portfolios (No. icma-dp2006-10). Henley Business School, Reading University. 1-32.

PRAKASH, A. J., CHANG, C. H., ve PACTWA, T. E. (2003). Selecting a portfolio with skewness: Recent evidence from US, European, and Latin American equity markets. Journal of Banking \& Finance, 27(7), 1375-1390.

QIN, Z., LI, X., ve JI, X. (2009). Portfolio Selection Based On Fuzzy Cross-Entropy. Journal Of Computational And Applied Mathematics, 228(1), 139-149.

SAMUELSON, P. A. (1970). The Fundamental Approximation Theorem Of Portfolio Analysis In Terms Of Means, Variances And Higher Moments. The Review of Economic Studies, 37(4), 537-542.

SINGLETON, J. C., ve WINGENDER, J. (1986). Skewness Persistence In Common Stock Returns. Journal Of Financial And Quantitative Analysis, 21(03), 335-341.

STEINBACH, M. C. (2001). Markowitz Revisited: Mean-Variance Models In Financial Portfolio Analysis. SIAM Review, 43(1), 31-85.

USTA, I., ve KANTAR, Y. M. (2011). Mean-Variance-Skewness-Entropy Measures: A Multi-Objective Approach For Portfolio Selection. Entropy, 13(1), 117-133.

WANG, S., ve XIA, Y. (2002). Portfolio Selection And Asset Pricing (Vol. 514). Springer Science \& Business Media.

XIDONAS, P., ASKOUNIS, D., ve PSARRAS, J. (2009). Common Stock Portfolio Selection: A Multiple Criteria Decision Making Methodology And An Application To The Athens Stock Exchange. Operational Research, 9(1), 55-79.

YARALIOĞLU, K. (2004). Uygulamada Karar Destek Sistemleri. İlkem Ofset, İzmir, ISBN, 975-270. 
YUE, W., ve WANG, Y. (2017). A New Fuzzy Multi-Objective Higher Order Moment Portfolio Selection Model For Diversified Portfolios. Physica A: Statistical Mechanics and its Applications, 465, 124-140.

ZAKAMOUliNE, V., ve KOEKEBAKKER, S. (2009). Portfolio Performance Evaluation With Generalized Sharpe Ratios: Beyond The Mean And Variance. Journal Of Banking \& Finance, 33(7), 1242-1254.

ZHOU, R., CAI, R., ve TONG, G. (2013). Applications Of Entropy In Finance: A Review. Entropy, 15(11), 4909-4931. 